\title{
THE RATIONALE OF E-HEALTH EVALUATION: THE CASE OF NHS DIRECT
}

Hamid Alalwany and Sarmad Alshawi

Information Systems Evaluation and Integration Network Group (ISEing) Brunel Business

School, Brunel University, UK

Hamid.Alalwany@brunel.ac.uk

Sarmad.AlShawi@brunel.ac.uk

\begin{abstract}
An important area of research is that of the evaluation of e-health services. A holistic e-health evaluation framework should address the aspects that are hampering healthcare services from embracing the full potential of information and communication technologies towards successful e-health initiatives. Towards building a holistic evaluation framework for e-health services, this paper is intended to examine the rationale of e-health evaluation, as the paper argues that this aspect should be addressed first in the development of such a framework. NHS Direct which is one of the largest e-health services in the world has been chosen to discuss and validate a set of evaluation rationales and their applicability in practice.
\end{abstract}

Keywords Healthcare services, E-health, Evaluation framework, Evaluation process, Evaluation rationale.

\section{Background}

E-health is a very broad term encompassing various activities in an evolving field. This is reflected in the broad and various definitions of the term. An example of these definitions is the one that has been adopted by the World Health Organization. According to the Organisation, Ehealth can be defined as 'being the leveraging of the information and communication technology (ICT) to connect provider and patients and governments; to educate and inform healthcare professionals, managers and consumers; to stimulate innovation in care delivery and health system management; and, to improve our healthcare system' (Hans Oh et al. 2005).

The variety of e-health applications is considerable, ranging from a self-help guide about treating common health problems at home to a virtual clinic which allows diagnostic consultations between patients and practitioners at separate sites. In light of the dynamic and evolving meaning of e-health concept and the wide range of applications that the term e-health has covered, the questions are what the term e-health means and what is the e-health application that should be considered. In this paper although we employ e-health as a broad term, the scope will be limited to the service delivery aspect by electronic means of information, advice, and consultation.

E-health, which are basically enabled and driven by the use of information and communication technologies in healthcare, have the potential to change the healthcare industry worldwide in terms of their infrastructures, and the costs and quality of services (Wickramasinghe and Misra, 2004; Wickramasinghe and Goldberg, 2004). Despite the potential that e-health may bring to the healthcare sector, the sector is the slowest in moving to the form of e-health among other government services. Skinner (2003) argues that the slow progress is related to the fact that

Hamid Alalwany and Sarmad Alshawi

The Rationale of E-health Evaluation; The Case of NHS Direct 
healthcare does not have the standards in place that other sectors do. Holliday and Tam (2004) have a broader explanation; they see that slow progress is more related to institutional, cultural and financial factors.

An important area of research is that of the evaluation of e-health services. It could contribute to important knowledge that can be used to support the value of existing e-health projects, and to increase the quality and efficiency of future e-health initiatives. Despite its importance, the evaluation of e-health services as many researchers agree, is both an under developed and under managed area in theory and practice (Brender, 2006; Friedman and Wyatt 2000). This study forms a part of a research that aims to develop, and assess a holistic evaluation framework for ehealth services. Towards this aim, the objectives of this paper are; addressing the challenges in developing such a framework, examining the rationale of e-health evaluation, as the paper argues that this aspect should be addressed first in the development of such a framework, and discussing and validating a set of evaluation rationales and their applicability in practice.

\section{Research Approach}

According to Lowery \& Evans (2004) and Myers \& Avison (2002) that selecting an appropriate research approach is about setting a research strategy considering the underlying characteristics or assumptions about what constitutes valid research. Such strategy should guide the researcher through the research process by embodying a particular style and employing different research methods. The research in this paper comprises of two parts. Part one is designed to address the challenges in developing an e-health evaluation framework, and examining the rationale of ehealth evaluation. Part two adopts case study methodology since it provides the opportunity to investigate e-health evaluation rationales in depth through a series of interviews, document analysis and archival records. The aim of this part is to analyze, and validate the applicability of the proposed evaluation rationales for e-health evaluation in the developed countries.

In part one, systematic database searches include but not limited to Emerald, ScienceDirect, and SpringerLink have been undertaken to identify the literature related to e-health evaluation. Suitable papers will be selected, and critically analysed to aid the aim of this part. The suitable articles and empirical case studies have to be carefully selected; specifically looking at those that intended to evaluate e- services in a healthcare context. The need for the published empirical data is important because of the current and rapidly evolving nature of the e-health field.

In part two, a case study has to be used to collect primary data. Yin (2003) lists six methods to collect data in case study methodology, they are; documentation, archival records, interviews, direct observation, participant observation, and physical artefacts. Many researches (Brewer \& Hunter, 1989, Creswell, 2003; Yin, 2003) show the limitations of using single method in addressing more than one disciplinary perspective and suggest the multiple methods of data collection to get more reliable and consistence research conclusions. The methods which have been selected for our case study are documentation and archival records, as well as limited use of semi-structured interviews to cover specifically the technology dimension of evaluation.

The collected data is essential to verify the finding of part one, and to critically analyse, and validate the applicability of the proposed evaluation rationales for e-health evaluation in practice.

\section{The case study}


The case study which has been chosen for this paper is concerning an e-health service called NHS Direct. NHS Direct service is a 24 hour, confidential telephone, online and interactive digital TV health advice and information service. The service is provided now by the NHS Direct Trust in United Kingdom and it is available through England and Wales. Since its launch in March 1998, NHS Direct has grown from small-scale pilots to being one of the largest healthcare services in the world. The concept of NHS direct may be summarized by the following statement of the NHS Executive, "The principle is to provide people at home with easier and faster advice and information about health, illness and the NHS so that they are better able to care for themselves and their families" (NHS Executive, 1998).

The NHS Direct telephone service has handled almost 5 million calls during the year April 2007 till March 2008. NHS Direct Interactive, a digital satellite health information channel, is now available to some 18 million homes. The NHS Direct website has received over 30 million unique visits during the year April 2007 till March 2008 (NHS Direct Trust, 2008).

The health information provision on the website includes:

- Self-help guide about treating common health problems at home;

- Heath encyclopedia which allow users to search for a treatment or condition by using one of four search options;

- Comparable choices of services available for specific treatment or condition available for different conditions;

- Common health questions;

- Hot topics on the latest health issues;

- Searchable database of local health services e.g. GPs, hospitals, dentists, pharmacies;

- Online health enquiry service.

\section{E-health Evaluation challenges}

The research in the area of e-health evaluation is a complicated and difficult subject (Brender, 2006; Friedman and Wyatt, 2000). The complexity and difficulty lies in the challenges encountered at the intersection of three research fields, each well-known for its complexity; healthcare services, information systems, and evaluation methodologies. Healthcare services are characterized by having many stakeholders which are working in different disciplines and pursuing different goals (Alvarez, 2003; Connell and Young, 2007; Ray, 2007). Healthcare services are also dictated by complex regulations, especially those that apply to directly manage patients' information. The medical knowledge itself and methods of healthcare delivery are changing rapidly and require a high degree of formalized working practices (Friedman and Wyatt, 2000). The regulations of healthcare services particularly in developed countries is complex in its diversity and wide ranging in its scope, ruling the relation with patients, health professionals, the public, taxpayers, employers, educators, regulators, and many others across the country. The medical knowledge is an enormous and dynamic field, Mcconaghy (2006) states that the medical knowledge doubles approximately every five years. Moreover the main aspects of this knowledge require an interactive environment to be transferred or practiced.

Information systems and its evaluation as many researcher (Serafeimidis and Smithson, 2000; Jones and Hughes, 2001) assent is another complicated and difficult research field. Symons and Walsham (1988) argue that the complexity is due to the multiple perspectives involved, and the difficulties of quantifying benefits. Willcocks (1992) has a similar view but he also believes that 
the complexity of information systems evaluation is changing and becoming more and more complex nowadays. This is because the nature of information systems investments is changing both in terms of technological capability and the benefits they can deliver, as well as in terms of diffusion in most aspects of society. The evaluation of information systems in public sector has proved to be even more complex as an accurate evaluation requires conducting the evaluation process in more challenging context. To overcome the complexity and difficulty of information systems evaluation in public sector, it is necessary to address and consider a number of evaluation challenges in the development of the required evaluation framework. The first of these challenges is the investigation of various perspectives (Jansen, 2005), which may not only require addressing and meeting the general needs of a target group such as citizens, but also requires including the specific needs of the specific target groups of citizens that are using a particular service. The second challenge in evaluating information systems in public sector is in identifying and quantifying benefits. Beynon-Davies, (2005) states that it is difficult to determine the precise benefits associated with information systems in public sector. An explanation to this lies in the different goals and objective of the information systems investments in public sectors, the benefits gained by these initiatives will be different as well, and the assessment of these benefits also vary according to the different perspectives of the stakeholders for the value of these benefits. The third challenge in evaluating information systems in public sector is the fact that in order for the evaluation to be proper, it should consider the social and technical context of use. This is a result of the opinion that information systems research is as much a social science as an information systems science (Mingers, and Stowell, 1997).

The establishment of an evaluation methodology is the last complex and difficult research field. The field is suffering from the limited experience of using methods, the unfamiliarity with evaluation techniques and the difficulty in interpreting results (Ballantine et al. 1999; Farbey et al. 1999; Powell, 1999). The limited experience of using methods in e-health evaluation is related to a certain extent to the gap between the theory and practice. Eng (2002) argues that this gap is a result of the tension between e-health research efforts in academic institutions and commercial organizations. He believes that the academic sector succeeds in developing scientifically rigorous evaluation methodologies, but these methodologies are not designed to answer real-world concerns. On the other hand, when commercial organizations conduct evaluations of e-health applications, they usually adopt methodologies with limited applicability to other situations. In adopting such methodologies, they maintain obtaining quick and practical answers because of market pressures.

Table (1) summarizes the challenges encountered at the intersection of healthcare services, information systems, and evaluation methodologies.

\section{\begin{tabular}{|l|l|l|}
\hline The Research Field & The challenges Encountered & References
\end{tabular}}




\begin{tabular}{|c|c|c|}
\hline Healthcare Services & $\begin{array}{l}\text { - Healthcare services are characterized by } \\
\text { having many stakeholders which are } \\
\text { working in different disciplines and } \\
\text { pursuing different goals. } \\
\text { - Healthcare services are dictated by } \\
\text { complex regulations. } \\
\text { - The medical knowledge is an enormous } \\
\text { and dynamic field. } \\
\text { - The main aspects of medical knowledge } \\
\text { require an interactive environment to be } \\
\text { transferred or practiced. }\end{array}$ & $\begin{array}{l}\text { Alvarez (2003) } \\
\text { Connell and Young } \\
(2007) \\
\text { Ray (2007) } \\
\text { Friedman and Wyatt } \\
\text { (2000) } \\
\text { Mcconaghy (2006) }\end{array}$ \\
\hline Information Systems & $\begin{array}{l}\text { - The multiple perspectives involved. } \\
\text { - The difficulties of quantifying benefits. } \\
\text { - The nature of information systems } \\
\text { investments is changing both in terms of } \\
\text { technological capability and the benefits } \\
\text { they can deliver, as well as in terms of } \\
\text { diffusion in most aspects of society. } \\
\text { - Consider the social and technical context of } \\
\text { use. }\end{array}$ & $\begin{array}{l}\text { Walsham (1993) } \\
\text { Beynon-Davies (2005) } \\
\text { Jansen (2005) } \\
\text { Willcocks (1992) } \\
\text { Mingers, and Stowell } \\
(1997)\end{array}$ \\
\hline $\begin{array}{c}\text { Evaluation } \\
\text { Methodologies }\end{array}$ & $\begin{array}{l}\text { - The limited experience of using methods. } \\
\text { - The unfamiliarity with evaluation } \\
\text { techniques. } \\
\text { - The difficulty in interpreting results. }\end{array}$ & $\begin{array}{l}\text { Ballantine et al (1999) } \\
\text { Eng (2002) } \\
\text { Farbey et al (1999) } \\
\text { Powell (1999) }\end{array}$ \\
\hline
\end{tabular}

Table (1) The challenges encountered at the intersection of healthcare services, information systems, and evaluation methodologies

\section{Towards an Evaluation Framework for E-Health Services}

The evaluation in the area of e-health services as many researchers argue, is dominated by economic and organizational aspects, has no standard framework for evaluating the effects and outputs of implementation and use, and the area in general is both under developed and under managed in theory and practice (Brender, 2006; Eng, 2001; Friedman and Wyatt 2000; Rahimi, and Vimarlund, 2007). Nevertheless, there is a wide range of information system evaluation frameworks, some of them were proposed and used in a healthcare context.

Existing evaluation frameworks that have been proposed or used in e-health context are suffering from many limitations. These limitations include, that they are either designed to focus particularly on the supply side of the healthcare services (organizational perspective) or they are designed to target a specific user or a specific application of an e-health initiative. Moreover, the healthcare dimension is either ignored or not fully considered in the design and the implementation of these evaluation frameworks.

Working towards building a holistic evaluation framework for e-health services that deals 
effectively with e-health evaluation challenges and overcomes the limitation of the existing evaluation frameworks, this paper examines the rationale of e-health evaluation, as the paper argues that this aspect should be addressed first in the development of such a framework.

\section{The Rationales of E-health Evaluation}

The rationale of e-health evaluation is about identifying the general basis of the evaluation and decides on why to evaluate. The rationale of e-health evaluation varies from one case to another and it is vital for an organization to determine as early as possible on the priorities of the evaluation questions. According to Heathfield et al. (1998), there are three types of rationale for conducting evaluation in the field of e-health, which are: maintain accountability for expenditure of resources; develop and strengthen performance of health organizations, individuals and/or systems; and build up new knowledge.

Maintain accountability for expenditure of resources is about assessing the value of governments' investments in the field of e-health. Governments have put considerable financial and human resources behind the development of e-government services; e-health services are taking top priority and receiving the large portion of these investments in most developed countries (Mitchell, 2000: Pan American Health Organization, 1999). In order to make such investments worthwhile, governments should have clear objectives in terms of outputs and the necessary financial and human resources to deliver specific goals by which they can justify these investments. Wimmer et al. (2008) indicated the importance of maintaining accountability for expenditure of resources as rational for evaluation. They believe that there is ambiguity regarding the value of these investments, and for whom, the value is needed first; they also believe that despite substantial investments of public funds, proper frameworks to monitor and evaluate the efficiency as well as benefits of such investments are lacking.

Developing and strengthening performance of health organizations, individuals and/or systems is about assessing the performance of an organization, individual or system through a set of key performance measures. Performance measurement can be defined as "measurement on a regular basis of the results (outcomes) and efficiency of services or programs" (Hatry, 1999). Performance was considered as major issue in influencing the organizational perspective and employed in theory and practice in the assessment of e-health services.

Developing and strengthening performance requires continuous performance assessment by adopting one of the performance evaluation approaches which is a challenging task in any performance evaluation. The most of existing performance evaluation approaches based on traditional accounting measures of performance. These measures suffer from the lack of comprehensiveness and the limited focus on long-term and outcome measures (Jones et al. 2006; Wong-On-Wing et al. 2007). In contrast to traditional performance evaluation approaches, the balanced scorecard (BSC) is proposed by Kaplan and Norton (1992) to address some of the limitation of the traditional performance evaluation approaches. The BSC is a multi-dimensional performance evaluation approach which is intended to evaluate organization performance from four different perspectives: the financial perspective, the internal business process perspective, the customer perspective, and the learning and growth perspective. Because the BSC provides 'a set of performance measures that gives top managers a prompt and comprehensive view of organization performance, it is one of the popular approaches in healthcare evaluation (Aidemark, 2001). 
Building up new knowledge is quite a general rationale for conducting evaluation in the field of e-health; it is an evaluation that contributes to the acquisition of details and understanding a particular discipline or field. Healthfield et al. (1998) highlighted the significance of such rational in the evaluation of e-health services, they stated, evaluation is not just about assessing the accountability for expenditure of resources, but also for development and knowledge building, knowledge that improves our understanding of the role of information systems in health care and develops our ability to deliver high quality systems that offer a wide range of benefits. Healthfield et al. (1998) suggest a multi-perspective, multi-method approach to conduct an evaluation that aims to Building up new knowledge. They believe that by using a multiple methods and involving diversely constituted research teams, it is possible to address a broad number of issues and produce an integrated evaluation.

Other authors (Brender, 2006; Kazanjian and Green, 2002) have suggested a decision-making as an important rationale for e-health evaluation. This rationale is about providing the basis for decisions regarding an e-health system under investigation or its implementation context. The Health Technology Assessment Framework proposed by Kazanjian and Green (2002) is an example of such evaluation. The framework was suggested to guide rational decision-making about the adoption of new e-health initiative. The framework is based on three questions: Who; What for; and How much and for whom? By answering theses questions, the evaluator should identify the main stakeholders that are affected and affected by the adoption of an e-health imitative, determine the purpose and value of it, and identify and quantify its benefits. The main dimentions of the framework are; population at risk, population impact, economic concerns, social context (including ethical, legal, and political concerns), and technology assessment information.

The last but not the least rationale for e-health evaluation is Friedman and Wyatt (2000) rationale, they argue that the core rationale of conducting evaluation is promotional; it is about encouraging the use of information systems in healthcare through assessing the risks and benefits for both users and government institutions.

Table (2) summarizes the main rationales for conducting evaluation in the field of e-health. Chosing one or more of these rationales for evaluation is determined by the most important question or questions for the evaluation. Based on the evaluation rationale, the evaluation process may take different time frames, deploy a particular evaluation method, require a qualitative approach, a quantitative approach, or both for data collection, and consider one or more than one perspective.

\begin{tabular}{|l|l|l|}
\hline & \multicolumn{1}{|c|}{ The types of rationale } & \multicolumn{1}{|c|}{ References } \\
\hline & $\begin{array}{l}\text { Maintain accountability for expenditure of } \\
\text { resources }\end{array}$ & $\begin{array}{l}\text { Heathfield et al. (1998) } \\
\text { Wimmer et al. (2008) }\end{array}$ \\
\cline { 2 - 3 } & $\begin{array}{l}\text { Develop and strengthen performance of health } \\
\text { organizations, individuals and/or systems }\end{array}$ & $\begin{array}{l}\text { Aidemark, (2001) } \\
\text { Heathfield et al. (1998) } \\
\text { Wong-On-Wing et al. } \\
\text { (2007) }\end{array}$ \\
\cline { 2 - 3 } & Build up new knowledge. & Heathfield et al. (1998) \\
\hline
\end{tabular}


July 13-14 2009, Crowne Plaza Hotel, Izmir

\begin{tabular}{|c|c|c|}
\hline \multirow[t]{2}{*}{ Rationale } & $\begin{array}{l}\text { Decision-making regarding an e-health service } \\
\text { or system under investigation or its } \\
\text { implementation context. }\end{array}$ & $\begin{array}{l}\text { Brender, (2006) } \\
\text { Kazanjian and Green, } \\
(2002)\end{array}$ \\
\hline & $\begin{array}{l}\text { Promote the use of information systems in } \\
\text { healthcare }\end{array}$ & $\begin{array}{l}\text { Friedman and Wyatt, } \\
(2000)\end{array}$ \\
\hline
\end{tabular}

Table (2) summarizes the main rationales for conducting evaluation in the field of e-health services

\section{The Case Study Findings}

The rationale of evaluation initiatives in our case study (NHS Direct) is changing while the service is growing from small-scale pilots to its size now as one of the largest healthcare services in the world. The rationale of evaluating the pilot sites of the NHS Direct's telephone service is concerned with how rather than whether the service would be implemented. Although the project executives believe that piloting was used effectively, Ministers decided that implementation and the roll-out of the service would proceed in a tight timetable alongside piloting. This prevents the opportunity to make an effective use of the informal evaluation of pilot sites. However, the project executives claim that the key lessons of the evaluation are taken forward through an effective communication between the pilots' team and those implementing the roll-out of the service. The rationale of evaluating the NHS Direct's online service is relatively different from the telephone service. While piloting is used for very limited purposes, the evaluation results are of no use as there is no staging plan to enable the results to be fully assessed and incorporated in the roll-out of the service. The project executives believe that it is impossible to get useful results out of piloting and the service can be better evaluated in the light of the early operational period.

April 2004 signified the transformation of NHS Direct, bringing together 22 separate operations into a national organisation. This allows the integration of the NHS Direct's telephone service (Advice and Guidance) with NHS Direct Online and NHS Direct Interactive (The Digital TV Service). Since the role-out of NHS direct service across the three channels and prior to 2004, there are few assessment initiative. They are conducted at unit level and mainly focused on examining some quality aspects of the service provided by NHS Direct. The rationale of evaluation initiatives in the last few years is mainly concerned with performance measures. By April 2005, NHS Direct starts using a 'balanced scorecard' approach (Kaplan and Norton, 1992), to assess the organization performance through selected key performance indicators. The 'balanced scorecard' is one of the popular approaches in healthcare (Aidemark, 2001). It takes NHS direct about a year to implement the balanced scorecard, the process include, setting benchmark standards, and developing research audit and evaluation database. NHS direct claims that the aim of this process is to provide information on large-scale across the service and allow best practice and lessons learned to be shared nationally.

In general, the results of examining NHS Direct revealed uncertainty regarding "why to evaluate" before and in the early stage of the service development. The aim of the limited evaluation initiatives in these stages is to provide the basis for the decisions about the NHS direct service and its implementation context. This resonates with the view of Brender (2006) regarding what should be the main rationale of conducting evaluation in e-health services. The results also revealed that the focus of evaluation initiatives in later stages of using NHS direct service moved 
from quality aspect to business objectives employing a performance measurement system which would provide a set of measures that gives the board a fast and broad view of the organization. This resonates to a certain extent with the view of Healthfield (1998) that one of main rationale for conducting evaluation in the field of e-health is to develop and strengthen performance of health organizations, individuals and/or systems. Regarding "why to evaluate", the limitation of the evaluation initiatives for NHS direct service lies in the lack of comprehensive rationale strategy for evaluation during and before the roll-out of the service. The evaluation is also largely driven by organizational and external forces that required the justification of huge investments, and suffer from the lack of user involvement in the evaluation.

\section{Conclusion}

This paper argues that the first requisite towards developing a holistic evaluation framework for ehealth services is to deal effectively with the complexities, and overcoming the barriers through a multi stage strategy. The e-health services evaluation complexities are correlated mainly to the multi-disciplinary nature of the field and the challenges at the intersection of the three areas, each well-known for its complexity, healthcare services, information systems, and evaluation methodologies. The paper starts with a summarization for these challenges. Working towards building a holistic evaluation framework through a multi stage strategy, this paper examines the rationale of e-health evaluation, as the paper argues that this aspect should be addressed first in the development of such a framework. The paper then proposes a list of rationales for conducting evaluation in the field of e-health. Chosing one or more of these rationales for evaluation is determined by the most important question or questions for the evaluation. Based on the evaluation rationale, the evaluation process may take different time frames, deploy a particular evaluation method, require a qualitative approach, a quantitative approach, or both for data collection, and consider one or more than one perspective.

The case of NHS Direct is used to discuss and validate the applicability of the proposed evaluation rationales for e-health evaluation in practice. The results of examining the case study revealed uncertainty regarding "why to evaluate" before and in the early stage of the service development. The limited use of evaluation in these stages is to provide the basis for the decisions about the NHS direct service and its implementation context. In later stages of using NHS direct service the evaluation rationales moved from quality aspect to business objectives employing a performance measurement system which would provide a set of measures that gives the top management a fast and broad view of the organization.

The limitation of the evaluation initiatives for NHS direct service lies in the lack of comprehensive rationale strategy for evaluation during and before the roll-out of the service and the absent of efficient mechanism to make use of the evaluation outcomes. The evaluation is also largely driven by organizational and external forces that required the justification of huge investments, and suffer from the lack of user involvement in the evaluation. Taking into account that this study forms a part of a research project which is still in progress, the limitation of this study lies in the absence of thorough validation and examination of the whole set of evaluation rationales that has not been fully applied in the fieldwork. Hence, the proposed rationales require comprehensive validation which will be performed by the authors of this paper in the next stage of this research using a wider range of case studies and population sections. This will form the basis for further research. 


\section{References}

Aidemark, L.G.(2001) The Meaning of Balanced Scorecards in the Health Care Organizations, Financial Accountability \& Management 17(1): 23-40.

Alvarez, R.C. (2003), "The promise of e-health: a Canadian perspective", e-Health International, Vol. 1 No. 1, p. 4.

Ballantine, J. A., Galliers, R. D. and Stray, S. J. (1999) 'Information Systems Technology Evaluation Practices: Evidence from UK Organizations', in Willcocks, L. P. and Lester, S. (Eds.): Beyond the IT Productivity Paradox, John Wiley \& Sons: Chichester, England, pp.123-149.

Beynon-Davies. P. (2005) Constructing Electronic Government: the case of the UK Inland Revenue, International Journal of Information Management. 25(1). 3-20.

Brender, J. (2006) Handbook of Evaluation Methods for Health Informatics, Elsevier Academic Press Publications, USA.

Brewer, J., and Hunter, A.,(1989) Multi-method Research, A Synthesis of Styles, SAGE Publications, Newbury Park, CA.

Connell, N. and Young, T. (2007) Evaluating healthcare information systems through an "enterprise" perspective, Information \& Management, Volume 44, Issue 4, June 2007, Pages 433-440.

Creswell, J. W., (2003) Research Design. Qualitative, Quantitative, and Mixed Methods Approaches, SAGE Publications, Thousand Oaks, CA.

Eng, T. R. (2001). The e-health landscape: A terrain map of emerging information and communication technologies in health and health care. Princeton, NJ: The Robert Wood Johnson Foundation.

Eng, T. R. (2002) E-health research and evaluation: challenges and opportunities. Journal of Health Communication, Volume 7, pp. 267-272, Taylor \& Francis

Farbey, B., Land, F. and Targett, D. (1999) 'Evaluating Investments in IT: Findings and a Framework', in Willcocks, L.P and Lester, S. (Eds.): Beyond the IT Productivity Paradox, John Wiley \& Sons: Chichester, England, pp.183-215.

Friedman C, Wyatt J. (2000) Evaluation methods in medical informatics. New York: SpringerVerlag.

Hans Oh., Rizo, C., Enkin, M., and Jadad, A. (2005) What is e-health? A Systematic Review of Published Definitions, Journal of Medical Internet Research. Published online 2005 February 24. doi: 10.2196/jmir.7.1.e1.

Hatry, P. (1999) Performance Measurement: Getting Results. Washington, D.C.: Urban Institute Press, p. 3.

Heathfield H, Pitty D, Hanka R. (1998) Evaluating information technology in health care: barriers and challenges. BMJ 1998; 316(7149):1959-1961.

Holliday, I., and Tam, W. (2004) E-health in the East Asian tigers, International Journal of Medical Informatics, Volume 73, Issue 11-12, Pages 759-769

Jansen, A. (2005) Assessing e-government progress- why and what, published in the proceedings: Tessem, B, J. Iden og G. Christensen (red) NOKOBIT 2005. ISBN 82-8033026-7, ISSN 1504-1697

Jones, S., and Hughes, J. (2001) "Understanding IS Evaluation as a Complex Social Process: A Case Study of a United Kingdom Local Authority," European Journal of Information Systems, Vol. 10, No 1.

Jones, S., Irani, Z., Sharif, A., and Themistocleous, M. (2006) E-government Evaluation: Reflections on Two Organizational Studies, Proceedings of the 39th Hawaii International 
Conference on System Sciences

Kaplan, R. S. and. Norton, D. P.(1992) The Balanced Scorecard-Measures that Drive Performance, Harvard Business Review: 71-79.

Kazanjian A, Green CJ. (2002) Beyond effectiveness: the evaluation of information systems using a comprehensive health technology assessment framework. Computers in Biology and Medicine 2002; 32(3):165-177.

Lowery, D., \& Evans, K. G. (2004) The iron cage of methodology, Administration \& Society, 36(3), 306-327.

Mcconaghy, J. (2006) Evolving Medical Knowledge: Moving Toward Efficiently Answering Questions and Keeping Current, Primary Care: Clinics in Office Practice, Volume 33, Issue 4, Pages 831 - 837, Elsevier Inc.

Mingers, J. and Stowell, F.(1997) Information Systems: An Emerging Discipline? Information Systems Series, McGraw-Hill, London, pp. 239-266.

Mitchell, J.(2000) Increasing the cost-effectiveness of telemedicine by embracing e-health, Journal of telemedicine and telecare, 6 Suppl 1:S16-9

Myers, M. D., \& Avison, D. (2002) Qualitative Research in Information Systems. London: Sage Publications.

NHS Direct Trust, (2008) NHS Direct Annual Report \& Accounts 2007/08, A Year of Success.

NHS Executive (1998), "NHS Direct Website", available at: http://www.nhsdirect.nhs.uk/

Pan American Health Organization (1999) Setting Up Healthcare Services Information Systems: A Guide for Requirement Analysis, Application Specification, and Procurement. Essential Drugs and Technology Program, Division of Health Systems and Services Development. PAHO/WHO, Washington, DC; ISBN 9275122660

Powell, P. L. (1999) 'Evaluation of Information Technology Investments: Business as usual'. In Willcocks, L. P. and Lester, S. (Eds.): Beyond the IT Productivity Paradox, John Wiley \& Sons: Chichester, England, pp.151-182.

Rahimi, B., and Vimarlund, V. (2007) Methods to Evaluate Health information Systems in Healthcare Settings: A Literature Review, J Med Syst (2007) 31:397-432, Springer Science + Business Media, LLC 2007

Ray, S. (2007) Development of a framework towards successful implementation of e-governance initiatives in health sector in India, International Journal of Health Care Quality Assurance, Vol. 20 No. 6, 2007, pp. 464-483, $q$ Emerald Group Publishing Limited.

Serafeimidis, V., and Smithson, S., (2000) "Information Systems Evaluation in Practice: a Case Study of Organizational Change", Journal of Information Technology, 15(2), 2000, 93-105.

Skinner R. (2003) The value of information technology in healthcare. Frontiers of Health Services Management. Vol. 19, Iss. 3. Spring 2003.

Symons, V and Walsham, G. (1988) The evaluation of information systems: a critique. Journal of Applied Systems Analysis 15:119-132.

Walsham G.,(1993) Interpreting Information Systems in Organizations, John Wiley \& Sons, Chichester.

Willcocks, L. (1992) Evaluating Information Technology Investments: Research Findings and Reappraisal. Journal of Information Systems, 2(3), p. 243-268.

Wimmer, M., Codagnone, C., and Janssen, M. (2008) Future e-government research: 13 research themes identified in the eGovRTD2020 project, Proceedings of the 41st Hawaii International Conference on System Sciences

Wickramasinghe, N. and Goldberg, S. (2004) 'How M=EC2 in healthcare', International Journal of Mobile Commerce, forthcoming.

Wickramasinghe, N. and Misra, S. (2004) 'A wireless trust model for healthcare', International Journal e-Health, forthcoming.

Hamid Alalwany and Sarmad Alshawi

The Rationale of E-health Evaluation; The Case of NHS Direct 
Wong-On-Wing, B., Guo, L., Li, W., and Yang, D. (2007) Reducing conflict in balanced scorecard evaluations, Accounting, Organizations and Society 32 (2007) 363-377,

Yin, R.K., (2003) Case study research: Design and Methods Third Edition, Sage Publications, Thousand Oaks, CA. 